\title{
MySci Advisors: Establishing a Peer- Mentoring Program for First Year Science Student Support
}

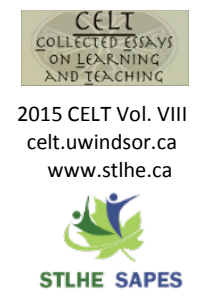

\author{
Kirsten Poling \\ University of Windsor
}

Would you like to help your students adjust to university life? Perhaps you are simply interested in allowing them to feel more integrated into a department right from the start of their first year? These were the types of issues that we were hoping to address when we founded the MySci Advisors Program, a peer-mentoring group for first year students in the Faculty of Science at the University of Windsor. This program is run entirely on a volunteer basis with no working budget, so if you were considering starting a mentoring program but have been concerned about the cost of doing so, this essay may be of particular interest to you. MySci Advisors is only in its third year currently, so this essay is meant to focus on the lessons we have learned in the early establishment of the program. I outline some of the practices we have adopted for the program, some of the changes we have had to make along the way and provide some early evidence of success. It is my hope that others may be motivated to also form such a program or use this information to assist in their own early endeavours.

\begin{abstract}
$\Delta$ s academic pressures rise but resources become Amore limited, universities have experienced an increase in class size and a corresponding decrease in the amount of personalised attention that students may receive, particularly in first year classes. In order to improve student success in these large courses, and to help improve student retention rates, many institutions are searching for ways to help students adjust to and thrive in the university environment. Students experience many different types of pressures when entering university and alleviating these pressures is an important part of ensuring that they persist in their education (Tinto, 1993). One possible avenue for enhancing both retention and success of students is the establishment of mentoring programs, as they have been shown to facilitate a successful social and academic transition to university (Heirdsfield,
\end{abstract}

Walker, \& Walsh, 2005) and reduce stress amongst students (Mekdessi, Curran, Lam, Grech, \& Nguyen, 2013).

Because transitioning to university often involves more than just a change in academic skills, we wanted to establish a mentoring program that would take more of a holistic approach and encompass many different facets of the adjustment to university life, from academic and study skills to social and career support. While there are many models for mentoring programs (Crisp \& Cruz, 2009; Gershenfeld, 2014; Jacobi, 1991), we chose to focus on transforming the learning experience by fostering a positive collaborative environment based on student peer mentoring in the Faculty of Science. Science programs often involve large firstyear classes with little sense of community. Furthermore, as a large number of science students 
vie for a limited number of spots in professional schools, there can be a heavy focus on competition. Thus, focusing our efforts on peer-mentoring in this Faculty would allow us to develop a program specific to Science needs while fostering a more community-minded approach in an inherently competitive environment.

\section{Why did we establish the MySci Advisors program?}

A major impetus for starting a mentoring program in the Faculty of Science at the University of Windsor was a survey conducted as part of a separate study, asking about the pressures that students faced in their transitional first year. During the Fall semester of 2011, students from science courses in various years of their programs were surveyed and asked to rate aspects of their academic experiences and attitudes, using a 5 point Likert scale. Out of 235 students, approximately $70 \%$ reported having moderate to high anxiety levels when entering first year courses and many reported that they did not feel that they had achieved their academic goals in their first year of university. In addition, these students were asked about various resources that they thought might have assisted them in their first year of university, including the possibility of a peer mentoring program. Students in their first and second year were more likely to say that a mentoring program would not have been helpful; however, approximately $25 \%$ of them did rate such a resource in the highest two categories of the Likert score in terms of the potential to help them at university (Figure 1).

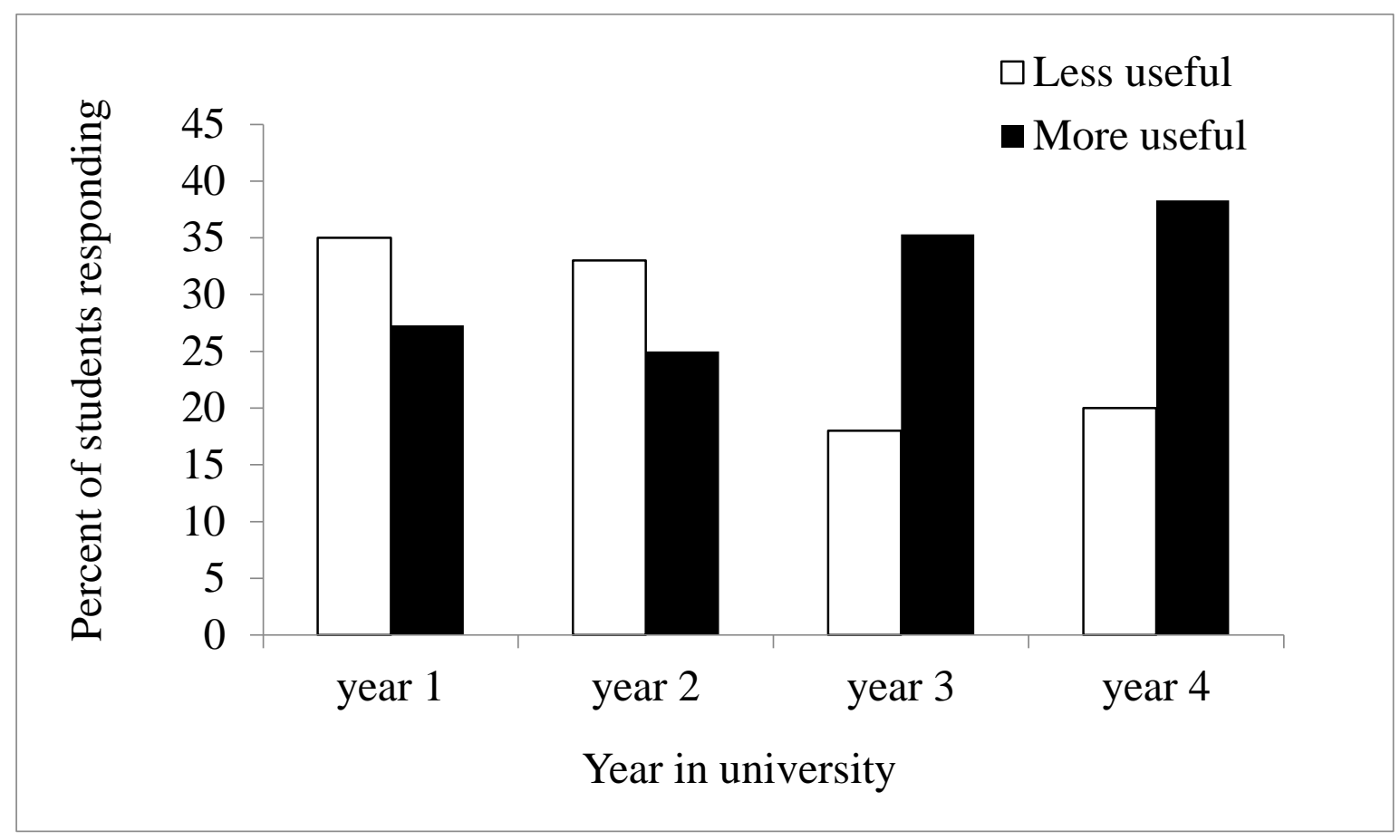

Figure 1

Responses of students asked whether they thought that a mentor would have been useful for improving their academic experience. Students who rated the idea a 1 or 2 on the Likert scale were grouped into the "Less useful" category and those who rated the idea 4 or 5 on the Likert scale were grouped into the "More useful" category. 
Interestingly, there was a shift in the importance attributed to the idea of a mentoring program. In third and fourth year, students were more likely to rate the idea of a mentoring program in the two highest Likert categories than in the lower rankings; $35-40 \%$ of the students in these years said that a mentoring program would have been useful in assisting them (Figure 1).

In addition, during follow-up interviews, many students commented on how they wished they had a peer mentor to help guide them through their early years of university. Many upper year students also expressed the desire to serve as mentors for younger students so that they could help less experienced students navigate the problems they would likely encounter.

Due to the results of this survey and an exceptionally eager group of students, we began planning the MySci Advisors program the following year, during the summer of 2012. Because MySci Advisors has only completed two complete academic years, there is not yet extensive quantitative data, so instead this essay will focus on current practices, in the hopes that sharing these methods with others will help in the formation of their own peer mentoring programs and also demonstrate that such a program can be established with few resources other than willing volunteers. I will share some qualitative observations and some of the lessons we have learned along the way that have allowed us to streamline our process while still providing what we feel is a valuable resource for our students.

\section{The MySci Advisors program}

The MySci program is run on an entirely volunteer basis and without a budget, so all efforts put into the program are cost free, except in terms of time spent. Our program is affiliated with the studentled Science Society on campus, so this offers us the ability to recruit both our mentors and mentees using their events and mailing lists, and allows us to book rooms on campus free of charge. Our mentoring program is not course-specific, nor is it meant to provide tutoring specifically. Rather our focus is on students sharing advice about how they have adjusted to university demands, how they have determined the best study skills, and the information that they have gathered along the way towards their specific academic and career goals. To that end, we pair our mentors and mentees on the basis of major foremost, but also on the basis of career interests; we also try to provide some compatibility on the basis of personal interests, so that students are able to form a successful relationship that will endure the course of the academic year. Each year we have approximately 50-80 pairs of mentors and mentees and most of these pairs last throughout the entire year; in many cases longer lasting friendships or mentoring relationships continue into subsequent years.

\section{The organising team}

The success of the program is entirely dependent on the presence of a coordinated organising team, which must be enthusiastic, organised and willing to put a concerted effort into the program. Especially during the beginning of the fall semester, when advertising, registration and pairing occur, there is a great deal of work to be done. In addition, over the course of an academic year, communicating with both mentors and mentees requires many emails, announcements via the learning management system and continual monitoring to ensure that all participants are informed of requirements and events. Typically the organising team consists of myself and three upper level undergraduate students. Because I want to maintain the peer aspect of the program, most of the advertising and communicating directly with students is done by the undergraduates on the organising team, while I conduct the background organisational tasks and anything that requires dealing with higher academic channels.

Sharing of tasks and keeping track of mentors and mentees is made simpler using online document sharing services such as Dropbox and 
Google Drive, but it is imperative to have a clear list of assignments for each member of the organising team. Initially, we tried to loosely distribute tasks; for example, each member of the team periodically paired mentors and mentees when they were inclined to do so, but we quickly discovered that with multiple people, more structure was required to avoid duplicate pairings and emails. In addition, with several people on the organising team, it is inevitable that one student will be more proactive and perform more of the tasks. To maintain equitable workloads, distinct tasks are necessary and help to ensure that no task remains incomplete.

\section{Mentor recruitment and training}

Mentors are recruited during the summer from third and fourth year students getting a major within the Faculty of Science; on our campus, this includes Biological Sciences, Chemistry and Biochemistry, Computer Science, Earth and Environmental Sciences, Economics, General Science, Mathematics, and Physics. In each year, between 50 and 90 upper year students have volunteered to be mentors. While we do have an application and interview process, these are largely informational and serve to give us an idea of the background and experiences of the mentors. We accept almost all people who volunteer, as they are all in good academic standing; however, some students are deemed unsuitable as mentors. Depending on responses to the interview questions, the organising team can decide that a mentor candidate has poor inter-personal skills or the wrong motivation for being a mentor (i.e. they wanted volunteer experience rather than actually wanting to help others). In this case they are not accepted to the program.

It should be noted that usually we receive more volunteers for mentoring than the number of students that request a mentor, suggesting that many students are not aware that they need assistance in their first year or are not successfully utilising all of the resources that are available to them. The fact that many students are not yet aware that they need assistance in their first year is consistent with the survey results that were reported earlier in this paper. Publicity for our mentoring program when recruiting first year mentees emphasises that students often later wish that they had utilised such a resource, making it clear that they should take advantage of these services now. In terms of recruiting mentors, the extra volunteers allow us to be more selective in our process of choosing mentors without the risk of leaving a first year student without a mentor.

In order to be assigned a mentee, mentors must attend a training session at the end of the summer or the beginning of the fall semester. This ensures that they are familiar with their responsibilities for the program and what role they should serve for their mentees. During the training, we provide them with a guidebook that includes information about campus resources, so that they can better guide their mentees as to where to seek help for a particular issue. Many of our mentors have commented that this has even helped them learn about campus resources they were not aware were there, so we believe that we are comprehensive in this regard. Mentors also are trained on appropriate confidentiality and safety issues. In addition, using role-playing exercises, the mentors model how they will assist first year students who are experiencing some of the common issues that may arise particularly during the first weeks of the semester; during these exercises, other mentors brainstorm together about ways to provide support for the first year student. During the training session, we stress the importance of using each other as resources and the fact that the organising team is a support network for mentors, so that they do not feel isolated when trying to help a struggling mentee. Because our mentors are volunteers, we feel very strongly that they should not feel solely responsible for their mentee's success or struggles.

\section{Mentee recruitment}

Mentees are recruited from the same departments as mentors, but with the additional extension that 
if they are getting a minor within the Faculty of Science, they could also apply to get a mentor in that same program. A minor at our institution typically requires many of the same core courses as a major, and students may share the same professional and academic goals, so we feel that those minors could also benefit from a mentor within the Faculty of Science. Mentees are also recruited during the summer at orientation events and via email, but typically we do not get a large number of students signing up during these events. For the recruitment of mentees, our most successful time has been during the first week of the fall semester, when students arrive on campus and sign up to participate in the program.

Mentees are also recruited throughout the fall and into the subsequent semester. As course loads increase and exam marks are handed out, we get more mentees that decide they do need help after all; this is when students are more receptive to hearing about available assistance programs like $\mathrm{MySci}$ and they see the value in talking to fellow students who have already determined how to get past academic difficulties. To ensure that the first year students know that they can still sign up for the program beyond the first week of the fall semester, we continue to advertise online and in first year classes. Because we usually have plenty of mentors that have signed up, we can pair up any new mentees easily as the academic year progresses.

Over the years, we have changed our recruitment process in an attempt to ensure that we would have more active participants. In our initial year, we had computer stations at welcome week events where first year students could directly sign up for the MySci program. However, in the excitement of welcome week, students signed up for many things, and ultimately many were not really interested in participating. This led us to modify our procedure so that there was a slightly more involved process; this now ensures that if students complete the extra actions necessary to sign up, they are truly interested in getting a mentor assigned to them. The current process involves getting names and emails and sending prospective mentees a subsequent email welcoming them to the MySci program. This email includes information about their responsibilities for returning correspondence from their mentors and includes a link where they can go to actually register for the program. We find that this has greatly reduced the proportion of mentees that are non-responsive to communications from the mentors and the organising team.

\section{Mentor/mentee matching and communications}

As mentioned previously, our primary criteria for matching mentors and mentees are their majors/minors and career goals. In the context of our program, we feel that major is of the greatest importance; while tutoring in courses is not a part of our program, we believe that the experiences and study skills are most likely to be similar within the same major. Career aspirations are also used as a major criterion because first year students can learn about the process of preparing for a particular career goal from their mentor, who would naturally be further along in the process. Of course, there are certain majors and career interests that are much more heavily subscribed than others and certain majors with low enrolments that are problematic. We have had problems pairing students in our Earth and Environmental Sciences majors as well as in Economics. While we have been able to pair some people in these programs, due to their smaller size, we often have either only mentees or only mentors. We continue to struggle with recruiting from these programs regardless of targeted recruitment of particular students, contact with the appropriate student clubs, or contact with the professors in these programs. If a requested match is not possible, we try to pair on the basis of minor or the highest degree of similarity in program. In such cases, both mentor and mentee are consulted independently to see if the potential match would be acceptable to them.

In order to be sensitive to any cultural issues and to ensure the highest possible comfort 
level in the relationship, when we gather information for pairings, we ask if students would prefer to be paired with someone of the same gender. As with major, we try to accommodate gender requests as much as possible. However, in certain programs gender requests are harder to fulfil (e.g. a female computer science mentor). As with the other pairings, we consult with both mentor and mentee to see if they can work with a different gender or if they would prefer to be paired with someone in a different but related program. Making these decisions before assigning a pair helps to reduce frustration or tension due to an inappropriate match, which does occur with other mentoring programs on campus.

Communication between mentor and mentee is a key component of MySci program. Once a potential match is identified, we email the mentor information about their mentee and tell them to make contact. We require mentors and mentees to meet in person the first time they communicate and that they both sign off on a mentor/mentee agreement. This agreement sets the ground rules for the relationship; as part of the agreement, mentors and mentees decide upon the primary form of communication they will use, how often they will communicate and if there are any issues that are off-limits for discussion. These agreements are then submitted to the organising team so that we could be sure that communication had been established and both parties were in agreement as to the context of the relationship that they were establishing.

During the first year of the MySci program, we had a number of mentees that did not respond to the mentors. This was frustrating for the mentors who were eager to help and led to the establishment of the enhanced application process for mentees that was mentioned previously. During the subsequent years, we have also made sure to specify during mentor training sessions that if a potential mentee does not respond within a week or two to the initial contact email, mentors should inform the organising team. The organising team then sends a follow-up email to say if no contact is established within a week, the potential mentee will be dropped from the program. This has reduced the waiting period for mentors and has helped reduce their frustration levels due to repeated attempts at contact.

\section{Monthly reports}

Because so many students are involved in the MySci program, we are not able to directly meet with all of them on a regular basis, but we want to ensure that mentors and mentees keep communicating and the relationship is working to everyone's benefit. To ensure that both of these objectives are being met, we require mentors to submit monthly communication logs; during training sessions, we stress that this is a required part of the program. Because our mentors are all volunteers, we do not want this requirement to be too onerous, so the report is simply a synopsis of how frequently communication occurs, topics that are discussed and any issues that arise that the mentor thinks may need further attention.

During the first year of MySci Advisors, we had mentors submit reports through a site constructed in the learning management system on our campus. While this was a convenient way to contact all of the mentors at once, it was not the most efficient way to read all of the reports and mentors occasionally had technical issues. In subsequent years, we have switched to a Google form, where everyone can submit their information, and then the responses are compiled into a worksheet. The organising team can send the link to the form in the reminder email shortly before the reports are due, and part of the form involves simply checking off what topics were discussed. This allows the mentors to more easily report on their activities while still leaving room for comments if more substantial issues have arisen. This also has allowed the organising team to more quickly scan the responses and look for any existing issues that needed to be remedied.

Mentees are not required to submit monthly reports, because we fear that requiring them to complete monthly assignments would 
further add to their stress as first year students. Although we do not require them to complete monthly reports, they are asked to participate in a voluntary assessment of their mentors and the MySci program as a whole so that we can use their feedback to improve how we serve the first year community. Because these reports were voluntary, we tend to get low participation, with approximately only $15 \%$ of mentees responding in a given semester. In addition, those that do respond are generally highly motivated to do so because they are quite enthusiastic about their experience so the information that we have gathered from those students may be skewed.

\section{What are the benefits and where do we go from here?}

We believe that the MySci Advisors program has benefitted students in the Faculty of Science, although at this point the evidence is largely qualitative. We have been very gratified to hear positive comments from both mentors and mentees about how the program has had a positive influence on their academic careers. Naturally it is easier to imagine the benefits for mentees; we have received numerous comments from the first year students about how their mentors have helped them succeed. These comments include reports of receiving reassurance in the intimidating university atmosphere, improvements in study and organisational skills, and helping to keep students motivated through their academic struggles, just to name a few. I believe that one of the most telling pieces of evidence is the fact that now that the first cohort of mentees are in their upper years, many of them are returning to be mentors. These students report that they feel that there have gotten through their academic careers in large part due to the advice and assistance they received from their MySci mentors and now they would like to be able to provide that support to others. In the future, I would like to solidify the analysis of these positive effects by quantifying retention rates of mentees and also examining the number of these students that continue their education beyond undergraduate studies. This would allow a concrete examination of the effectiveness of the program while adding to the limited number of mentoring programs that have been examined using rigorous research methods (Gershenfeld, 2014). Ultimately, I believe that the MySci program can play an important role in science student success by showing that the Faculty of Science is supportive of student needs; it may be more important to student satisfaction and persistence that students perceive that an institution is attempting to help them, regardless of a measured effect (Kuh, Kinzie, Buckley, Bridges, \& Hayek, 2006).

While the benefits to mentees are usually the focus of peer-mentoring programs, we have always felt that it is important that the mentors benefit as well, particularly since MySci is strictly a volunteer program. We have collected some preliminary qualitative data that suggest where the possible benefits are occurring; many mentors have reported gaining skills in communication, empathy, and exhibiting patience. Some mentors have specifically linked their gains to future careers; one mentor stated that helping someone develop academically can be useful to their future potential career as a high school educator. Many of the student volunteers who became mentors have also commented that they now see themselves more as an integral part of a community due to the fact that they were helping others and making a connection with new students. Many of our mentors do return for a second year if possible which attests to the fact that they are aware of the benefits of mentoring and enjoy helping new students. As with the mentees, I would like to quantify some of these effects by more rigorously examining data pertaining to outcomes and attitudes. There is a growing awareness that mentoring is, and should be, a reciprocal relationship (Colvin \& Ashman, 2010; Heirdsfield, Walker, Walsh, \& Wilss, 2008) and I think it is important to be able to document that MySci mentors are receiving benefits along with the mentees. This would also allow us to better serve the volunteers by addressing any dissatisfaction that 
may arise, although to date no volunteer has reported dissatisfaction with the way the program is being run.

Given the increasing number of students entering many universities and the lack of concomitant increases in resources, it is likely that students will continue to feel a great deal of stress and competition when entering university. A peer mentoring program such as MySci Advisors can make a large difference in terms of providing students with assistance and the belief that their institution is genuinely concerned about their needs. I will continue to run the MySci Advisors, with the intent of formalising the results, while not losing the friendly and helpful nature of the program.

\section{References}

Colvin, J.W., \& Ashman, M. (2010). Roles, risks, and benefits of peer mentoring relationships in higher education. Mentoring o Tutoring: Partnership in Learning, 18, 121-134. http://dx.doi.org /10.1080/13611261003678879

Crisp, G., \& Cruz I. (2009). Mentoring college students: A critical review of the literature between 1990 and 2007. Research in Higher Education, 50, 525-545. http://dx.doi.org/10.1007/s11162-0099130-2

Gershenfeld, S. A. (2014). Review of undergraduate mentoring programs. Review of Educational Research, 84, 365-391. http://dx.doi.org/10.3102/00346543135 20512

Heirdsfield, A., Walker, S., \& Walsh, K. (2005). Developing peer mentoring support for TAFE students entering 1st-year university early childhood studies. Journal of Early Childhood Teacher Education, 16, 423-
436. http://dx.doi.org/10.1080/1090102 0500413262

Heirdsfield, A., Walker, S., Walsh, K., \& Wilss, L. (2008). Peer mentoring for first-year teacher education students: the mentors' experience. Mentoring \& Tutoring: Partnership in Learning, 18, 109-124. http://dx.doi.org/10.1080/13611260801 916135

Jacobi, M. (1991). Mentoring and undergraduate academic success: A literature review. Review of Educational Research, 61, 505532. http://dx.doi.org/10.3102/003465 43061004505

Kuh, G., Kinzie, J., Buckley, J. A., Bridges, B. K., \& Hayek, J. C. (2006). What matters to student success: A review of the literature. Commissioned Report for the National Symposium on Postsecondary Student Success: Spearheading a Dialog on Student Success, National Postsecondary Education Cooperative. Washington, DC: U.S. Department of Education. Available from http://nces.ed.gov/npec/pdf/kuh_ team_report.pdf

Mekdessi R., Curan, B., Lam, B., Grech A., \& Nguyen M. (2013, July). Health sciences peer-mentoring: A student-staff-alumni collaboration. Paper presented at the $16^{\text {th }}$ International First Year in Higher Education Conference, Wellington, NZ. Retrieved from http://fyhe.com.au/past_ papers/papers 13/4C.pdf

Tinto, V. (1993). Leaving college: Rethinking the causes and cures of student attrition ( $2^{\text {nd }} \mathrm{ed}$.). Chicago: University of Chicago Press. 


\section{Acknowledgements}

The initial survey study of 2011 was supported by a Centred on Learning Innovation Fund 2011 from the Centre for Teaching and Learning at the University of Windsor and conducted under Research Ethics Board approval number 12-110.

Many thanks to the students who participated in the initial survey and of course, to all of those who participate in the MySci Advisors program. Establishing and administering the $\mathrm{MySci}$ Advisors would not have been possible without Jackson McAiney, Ruby (Rawa) Jamil and especially Sarah Hanik, who served as the main organisers and motivators for the inaugural years of the program.

\section{Biography}

Kirsten Poling is a Science Teaching and Learning Specialist in the Department of Biological Sciences at the University of Windsor. Her primary interest is in helping students realise their potential during their undergraduate experience. Her efforts to support students have resulted in extensive mentoring of nursing and biology students, research on new biology laboratory exercises and the use of Tablet PC computers to enhance student engagement, as well as the development of the MySci Advisors program. 


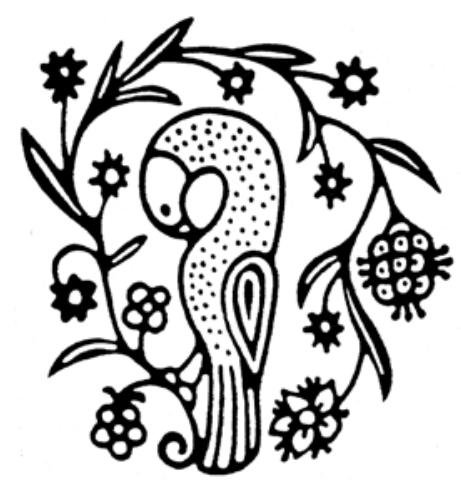

